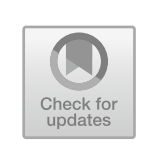

\title{
Cultural Literacy During COVID-19
}

Abstract As implementation of the CLLP was challenged by the COVID-19 pandemic, the DIALLS project included in the program an additional lesson in which children reflected on its impact on their social environment. In this chapter, the authors analyze how the children's artifacts express their understanding of the COVID-19 situation, including themes such as care and protection. The chapter focuses on how the students address empathy, tolerance, and inclusiveness under pandemic conditions. It starts by contextualizing the artifacts with international COVID-19 imagery and nationally similar or differing COVID-19 circumstances. Then, it analyzes the artifacts and their textual narratives.

Keywords COVID-19 · Pandemic conditions · Care · Protection

\section{Reporting AND Research ON THE COVID-I9 PANDEMIC AND ITS IMAGERY}

As our data collection for the Cultural Literacy Learning Programme (CLLP) was challenged by the COVID-19 pandemic in spring 2020, we chose to include an additional task in the program about the impact of the pandemic. In this additional task, students in some countries where this was possible were asked to reflect on the question: How can I be

(C) The Author(s) 2022

T. Lähdesmäki et al., Learning Cultural Literacy through

Creative Practices in Schools, https://doi.org/10.1007/978-3-030-89236-4_8 
empathetic, tolerant, and inclusive in pandemic conditions? The students visualized their reflections. Some of their works included captions which consisted of a title and short textual elaborations. In this chapter, we analyze how, in their artifacts, students who did this supplementary task reveal their understanding of cultural literacy themes in relation to COVID-19. In particular, we analyze how the students approached the task of depicting empathy, tolerance, and inclusion in this situation of worldwide emergency.

Since the COVID-19 task was an unplanned supplement to the CLLP, only three of the countries that participated in testing the program chose to carry it out: Lithuania, Cyprus, and Portugal. The data set is quite uneven, as some of the countries only gathered items made by one age or school group. Most of the COVID-19 images (28 artifacts) came from the oldest age group, roughly half each from Lithuania and the other half from Portugal. The fewest images were made by students in the second age group (four artifacts, all from Lithuania). In the youngest age group, apart from one Lithuanian image, all the artifacts were made by Cypriots. Since the artifacts from Cyprus (24) and Portugal (14) only included short titles or no descriptive captions at all, most of the textual elements we refer to in this chapter derive from the Lithuanian data. Altogether there were 57 artifacts in the COVID-19 data set.

In order to contextualize the images, it is worth noting that the COVID-19 pandemic yielded a wealth of imagery and research topics. National and international health campaigns provided images of health professionals in protective clothing and reminded citizens of the importance of handwashing and correct coughing and sneezing. Visualizations of the virus accompanied the news on the subject (Valko 2020) and artists interpreted the crisis from various viewpoints (McCarthy and O'Rawe 2020). Moreover, pandemic-related memes flooded social media platforms and the pandemic was reported to cause similar imagery in people's dreams (McKay and DeCicco 2020).

After the initial turmoil of lockdowns and state-imposed restrictions on people's free movement, many researchers analyzed the pandemic through humanistic, educational, or artistic lenses, investigating subjects ranging from mitigating the impact of COVID-19 to related humor (Academy of Finland 2020; University of Amsterdam 2020). Meanwhile, newspapers and magazines published calls for people to keep diaries of their experiences and reports on how museums and research centers started to document this "period of deep historical import [...] 
a time of both ascendant empathy and exposed prejudice, of collective fear for the present and collective hope for a brighter future" (Smith 2020, l; see also Landdeck 2020; Popescu 2020). NGOs, universities, and newspapers collected children's drawings reflecting the coronavirus pandemic (UNICEF 2020a; Staffordshire University 2020; The New York Times 2020). UNICEF even presented drawing one's feelings about the pandemic as a way to maintain one's mental health (UNICEF, Facebook post, 2020b), an approach that was mirrored in other reports (Richards 2020; Taylor 2020).

In journalistic and academic reports of a humanist perspective, the state of emergency was approached through disciplines such as history, education, aesthetics, science fiction, and popular culture. A recurring question in these speculative writings was what humanity might be able to learn from the pandemic (Kovalčik and Ryynänen 2020; Robinson 2020; Kale 2020; Callard 2020). Discussions about how the pandemic influenced minority rights mixed with reportage about how to feel connected during quarantine (Wilson and Frey 2020). Other reports highlighted the role of social media in alleviating boredom, fatigue, and fears during the pandemic. The Guardian, for example, recounted how the memes, jokes, and skits on the video-sharing app TikTok were a "surprise lockdown hit," where anarchy and absurdist jokes coexisted with health campaigns (Kale 2020). The New York Times noted that even high-profile institutions such as the Uffizi Gallery turned deliberately clownish on TikTok (Marschall 2020).

The lockdown procedures were similar in many countries. The three countries from which our COVID-19 data stems all introduced restrictions and safety measures such as quarantine, maintaining a safe distance, and wearing masks. "Social" (or physical) distancing encompassed refraining from social contact outside one's own household-a measure accompanied by the "stay home" hashtag in social media postings all over the world. In order to break chains of infection, kindergartens were closed in many countries and schools moved to remote learning. Workers who were able to do so also began to work remotely from home. The most fiercely protected, and hence isolated, groups included senior citizens.

As the pandemic continued, people increasingly discussed mental health. Researchers at the Vilnius University Psychotraumatology Center, for example, published a study that revealed that four in five Lithuanian adolescents (aged 13-18) experienced learning difficulties due to the pandemic. Furthermore, three in four adolescents indicated that their 
leisure activities were impaired and one in four adolescents reported having relationship difficulties within the family (Vilnius University 2020). Research in Cyprus likewise indicated a relatively high prevalence of generalized anxiety disorder and depressive symptoms in the Cypriot population during the COVID-19 outbreak. One researcher identified a statistically significant increase in major depressive symptoms among students and people aged under 21 , which was attributed to the fact that closing schools destabilized their regular study routine (Stylianou and Samouti 2020). Portuguese research on the state of public mental health due to COVID-19 also found increased levels of anxiety and stress (Paulino et al. 2021).

Altogether, the pandemic had a large-scale impact on students' lives, as is clear in the images they produced for our project. In what follows, first we provide a general overview of themes that the students discussed in their visual artifacts on COVID-19. Second, we discuss the artifacts in relation to the themes of empathy, tolerance, and inclusion by engaging in a closer reading of some selected images and captions. To conclude, we look at exceptions and peculiarities, to determine which ideas and experiences the project design captures and which understandings are probably beyond the scope of this particular research constellation.

\section{COVID-ig in Student Artifacts: Obeying Rules and Taking Care of Oneself and Others}

In our analysis, we initially categorized the COVID-19 images according to their visual theme. Some of the images fitted in more than one category, but one theme dominated in most. These visual categories were: Communication (2), scenarios (2), feeling and time (4) global cooperation (7), rules (10), home and family (12), and protection-in particular face masks (20). Since the captions added extra layers of meaning to the images, we also grouped the artifacts into two general themes: Obeying rules and taking care of oneself and others.

Communication features prominently in two drawings by Lithuanian students, one of the oldest age group and the other one of the middle age group. The first one drew two teenage girls keeping in touch via an "ancient" type of communication, two cups attached to a line; the second depicted a girl keeping in contact with her grandparents via a laptop computer. Furthermore, two of the drawings categorized as depicting "home and family" (both made by Cypriots of the youngest age group), 
also have captions referring to long-distance communication: "I will call you on Viber to share our news in the evening. We stay safe at home!"; "I love you but I am telling you from a distance."

Two further drawings depicted scenarios divided by a vertical line down the middle of the paper. In both, the left side of the image depicts a somewhat gloomier scenario (using color, e.g., gray and violet), while the right side is happier (e.g., in yellow). In both drawings, the positive scenario on the right depicts children happily playing outdoors. The left side depicts faces with the mouth turned downward in sadness in one and a medic wearing a face mask in the other.

Feeling and time was a notable feature in four artifacts that depicted the experience of waiting and isolation during lockdown. This was mostly done by referencing the passing of time. A group of Cypriots in the youngest age group, for example, created a colorful wheel titled "A clock that shows us when the quarantine will end and the coronavirus will disappear." Two Lithuanian students from the oldest age group depicted a person or a family trapped in a glass or an hourglass.

Global cooperation was depicted by one Lithuanian student in the oldest age group as people building a huge puzzle together. Eight other images by the oldest students (one from Portugal, the others from Lithuania) depicted or featured the globe, but not all of these were categorized under the theme of global cooperation, since some of the images also fitted in the category of protection/masks.

Rules was the third most common theme. Although many of the artifacts mentioned the rules or restrictions related to the pandemic in textual form, most of the visualizations categorized in this theme were produced by the youngest students in Cyprus. Many of these referred to the "three don'ts" that prevent the virus from spreading: Don't touch your mouth, nose, or eyes. The similarities of the images in this category suggest that they were made under rather specific instructions that deviated somewhat from the researchers' intention for this task. As such, they probably reflect the teacher's educational goals. Although some of these images are rather charming, they do not provide many opportunities for readings focusing on tolerance, empathy, and inclusion, as they lack deeper textual captions referring to these subjects (Fig. 8.1).

Home and family was the second most common theme, prominent above all in the artifacts produced by the youngest age group. A handful of the youngest Cypriot students glued together colorful paper cutouts made by tracing their own and their family members' hands in order 


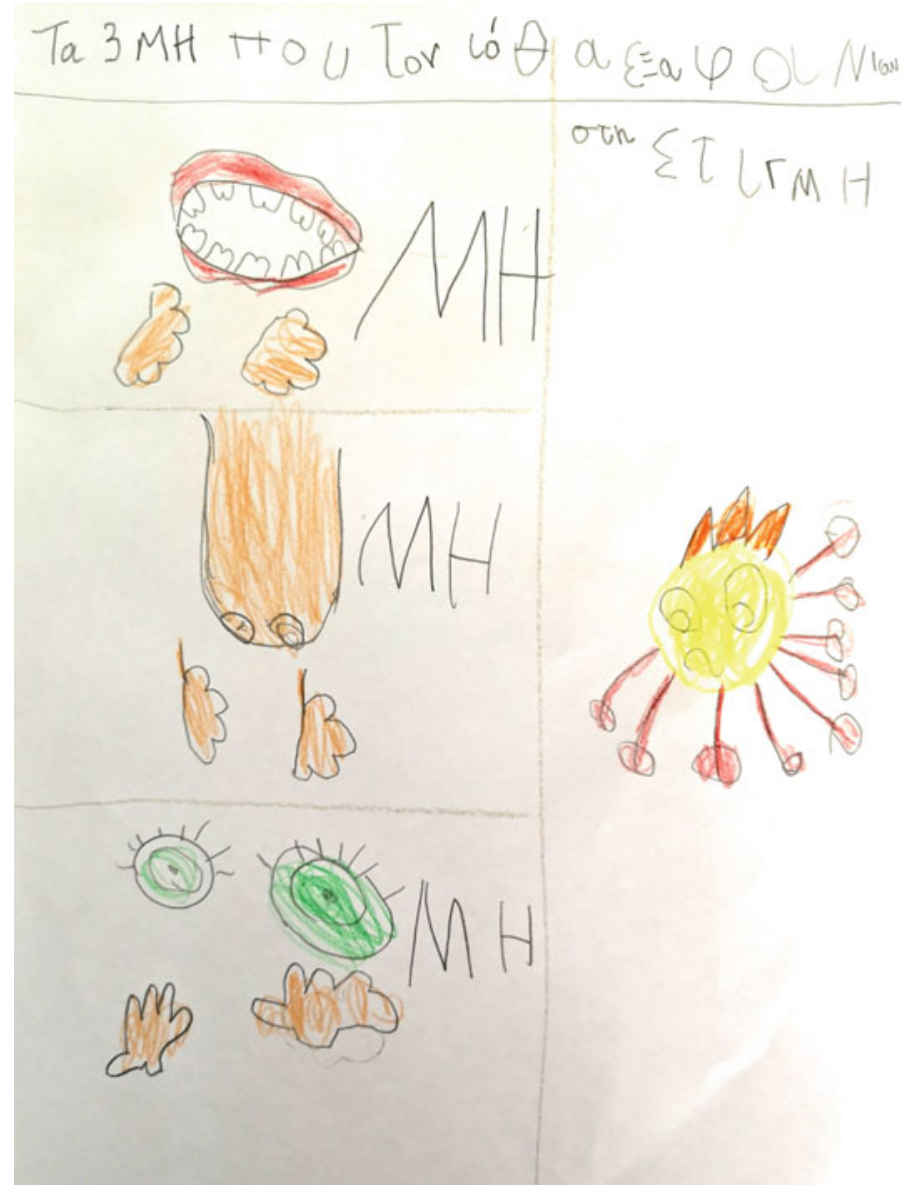

Fig. 8.1 "The three don'ts that will make the virus disappear at once: Don't, don't, don't" by a student from Cyprus, youngest age group

to show who was part of their immediate family. Another group of the youngest Cypriots all depicted similar images of seemingly happy people, defined as family, standing outdoors in the sun among flowers and butterflies, dressed nicely and colorfully. Only the captions of some of these images relate them to COVID-19 with phrases such as "we stay home" or "\#stayhome." 
Protection, or masks, was the most common visual theme within the COVID-19 artifacts. In the Portuguese data, a whole group of students painted declarations on face masks. Furthermore, many of the Lithuanian students depicted face masks in images that showed medics and ordinary citizens in protective gear. The accompanying captions often address the rules and regulations and refer to the importance of wearing masks as an example of good conduct.

Visualizations of the virus were also very common and appeared in many of the different categories. This attests to the fact that the students, even the youngest ones, were clearly aware of how the virus has been depicted in the media and news reporting, as the images all depicted a round form with similar round appendages (Valko 2020).

Obeying rules and taking care of oneself and others were the two main themes that we identified from the images and the captions. All the artifacts referenced the need to adhere to the regulations related to the pandemic, or the selfless effort it demanded of individuals: Behaving sensibly and following the rules would ensure that everyone, oneself included, might get through the situation and resume normal life. We give more examples of this in the next section, where we focus on how the students discussed empathy, tolerance, and inclusion in their COVID-19 artifacts.

\section{Empathy, Tolerance, and InClusion in the Context of the Global Pandemic}

The task students had was to reflect on the question: How can I be empathetic, tolerant, and inclusive in pandemic conditions? The COVID-19 imagery produced by the students in our project was quite uniform in terms of these central attitudes of cultural literacy. Generally, the artifacts emphasized obedience, community effort, and the idea that the restrictions were for the common good. There is a strong focus on conformity in the data. The images and captions promote compliance with the national health campaigns and WHO guidelines and reflect the educational stance of these campaigns.

Tolerance was explicitly mentioned in six captions. In the interplay of word and image, the students often promoted the view that the restrictions and guidelines or "rules" drawn up during the pandemic were something to be tolerated. Yet, tolerance was often unspecified, as exemplified by a Lithuanian student of the oldest age group, who first states 
the importance of staying safe and then adds that this includes adherence to the rules:

At the moment the most important thing is to stay safe. I think that all people adhere to the rules: Wear masks, keep [your] distance, wash [your] hands [when] coming home. Tolerance is most important in such times. Elderly people are in danger, that's why my mom buys everything for the neighbors. I help my mom to disinfect the stairwell. The Covid virus is very dangerous, that's why we need to follow strict rules, and help each other. Probably we will succeed to survive and live our lives as before.

The drawing accompanying this caption depicts a woman sitting on a giant virus and wearing a face mask. In her hand, she holds a drooping red flower and in front of her we see the world, a blue planet with green continents. From behind the globe, a flock of birds appears (Fig. 8.2).

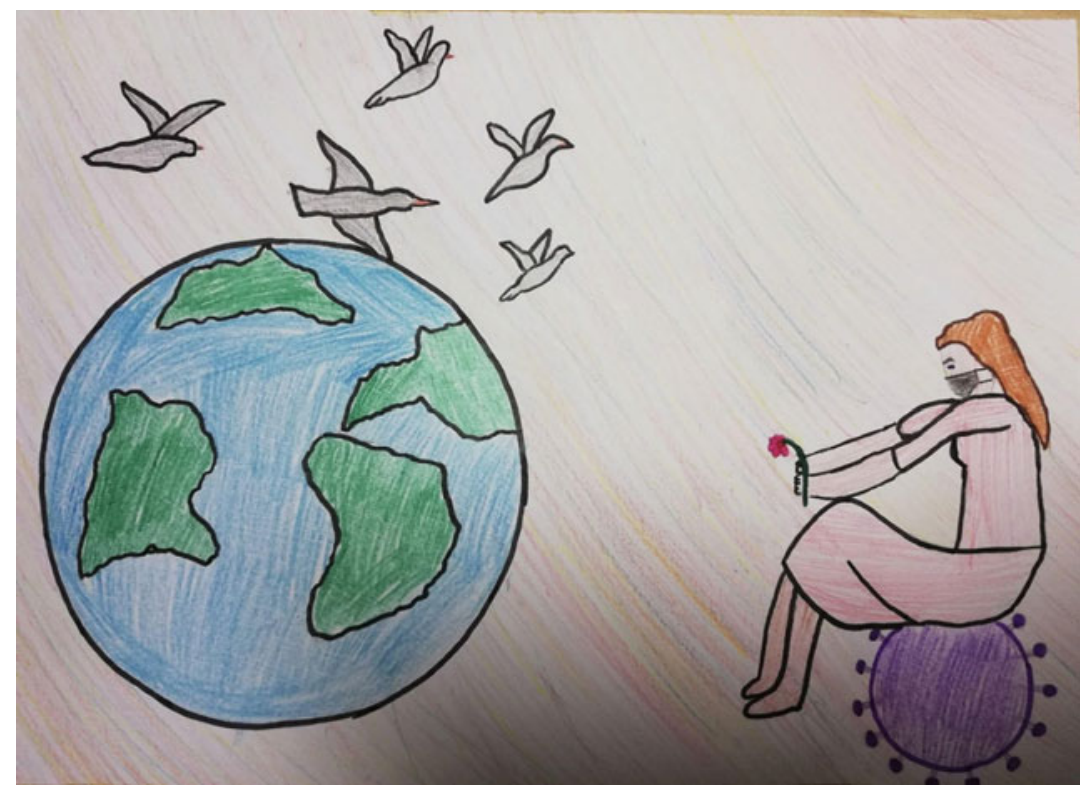

Fig. 8.2. Drawing by a Lithuanian student of the oldest age group with the title "We are all responsible" 
The image is full of strong symbols. The drooping flower indicates sadness and hardship. The woman's sitting pose may be interpreted as a sign of endurance, of "sitting it out." And the birds may be seen as signs of freedom. Hopefulness is a strong element in many of the artifacts in this data set, as exemplified by another caption that a Lithuanian student in the second age group added to her artifact. In it, she openly rejoices about springtime, which is a common symbol of new life and change for the better: "Blooming apple trees around as well as gently swaying grass. Spring is coming!!! I want to stop the pandemic very soon and children could play in the courtyard."

The image accompanying this rather cheerful text depicts people greeting each other respectfully when walking in the park. Instead of shaking hands, they place their hands on their chests. Respect and civility are mentioned as attitudes that are related to tolerance.

As a rule, the students mostly related tolerance to tolerating the restrictions imposed upon one's own personal freedom. It was framed as something to be done for the greater good, the good of the communityespecially to save the lives of elderly people. Elderly people and medics were the two most commonly mentioned groups of "others" in all these artifacts. In both cases, these demographics are presented as reasons to endure the restrictions. They are in most danger, or on the front line; adhering to the rules particularly protects their lives. People from these two groups are depicted as the objects of empathy, as in the following caption by a Lithuanian student from the oldest age group:

My family's greatest help to each other, I think, is to take care of each other, to keep the risk of virus infection at home as low as possible, and not to forget each other, because that's very important now, especially for grandparents or just older people, because I think they are undergoing very difficult times, and we shouldn't allow them to go through it alone. Every call can cheer them up, knowing that someone cares about them, in my opinion, means a lot to them.

Empathy toward medics is illustrated in this text excerpt, likewise by a Lithuanian student in the oldest age group:

We go shopping one by one. Let's be tolerant, distancing on the line, don't touch the thing which we don't intend to buy. Coming back home, wash our hands, disinfect, remove our masks. My family is very empathetic to doctors, we stay at home and save each other. 
In some instances, determining the subjects and objects of empathy is harder. An example that relates tolerance and empathy explicitly to elderly people, without being clear about whether they are the objects or subjects of this disposition, it is given by a Lithuanian student in the oldest age group, who drew a "no touching" sign accompanied by the text: "Older relatives at risk buy the necessary goods, do not allow them to visit public places or use public transport. This shows a high level of tolerance and empathy for people in that age group." This use of the concepts of tolerance and empathy could be seen as rather paradoxical, since the restrictions on older people exclude them from public spaces. Although the lawmakers had the best interest of this group in mind, they seriously hampered old people's rights to self-determination.

In many of the COVID-19 artifacts, empathy also becomes something connected to the shared feelings of sadness caused by isolation. The ones feeling empathetic are the students and the people that they associate themselves with, expressed in the pronoun "we," as the following text written by a Lithuanian student of the oldest age group illustrates:

In such a situation in which we are right now, we have to be more tolerant. Each of us has similar feelings, understanding better. We feel a little bit sad, not having possibilities to meet our friends, family members who live separately. Our lifestyle has changed, so we need to start to live in another way than before.

Altogether, then, there is a considerable amount of definitional vagueness in the manner in which the artifacts reference the concepts of tolerance, empathy, and inclusion. This can also be seen in a statement that begins the caption of an older Lithuanian student: "During the quarantine, I am empathetic when I don't leave home." The same vagueness is visible also in another caption by another older Lithuanian, who describes the suffering that the virus has caused via "the loss of loved ones, illness and isolation" and who then goes on to state that " $[\mathrm{t}]$ here is a great deal of empathy and tolerance at this difficult time."

Representations of inclusion were somewhat harder to track within the data. Inclusion was not referenced explicitly by any of the captions, but there are many visualizations of family and references to a "we," as the quotes above exemplify. As a Lithuanian student of the youngest age group put it: 
Our family stays at home all the time. Other people are afraid to go outside. Streets seem empty. It's good to stay at home not meeting corona[virus]. But everybody likes everybody: Saying good words to each other. That's why I drew a lot of hearts. Sometimes a boy goes outside to play football. But his behavior is not good, he did not follow the rules. It would be nice if somebody could tell him about that.

In this case, "our family" and "other people" are aligned by shared fear of the virus, their adherence to the rules, their goodness, and the nice things that they say to each other. Their behavior is contrasted with that of the boy who goes out to play football. One could read envy into the sentence describing him but also simple concern for the boy's health. After all, he might not know better. There is no hint of the desire to engage in dialogue with the boy or to question the rules imposed by the state. As such, this image and caption might stimulate discussion, but do not reflect dialogic engagement with differing viewpoints as such.

Visually, the most powerful signs of inclusion are the depictions of global joint effort to overcome the pandemic. These images of people holding hands across the globe illustrate the need to stand united and to work together. One student explicitly depicts people of different ethnic backgrounds standing united by the COVID-19 situation (Fig. 8.3).

Since our data on this subject is relatively small and uneven, it is nearly impossible to make comparisons between age groups or countries. Most of the quoted captions stem from the Lithuanian data, as the Lithuanian artifacts included much longer captions than the ones from Cyprus, while the Portuguese artifacts include only short titles or no captions at all. It might thus be more relevant to identify similarities within images made in the same classrooms or under peer influence than to decipher cultural differences. Nevertheless, newspapers have reported similar iconography on the pandemic in children's drawings from around the world. Gulf News, which showed images drawn by children in Bosnia and Herzegovina, Japan, Australia, Morocco, Cuba, Switzerland, South Africa, Germany, Spain, Italy, and Chile, summarized this observation in a news item titled "COVID-19: Children's drawings from lockdown show the world what they miss most: Regardless of where they are, the themes are often the same" (AFP and Lacsina 2020). The same news was reported by Reuters, who listed grandparents, friends at school, football, and green open spaces among the things most dearly missed by children 


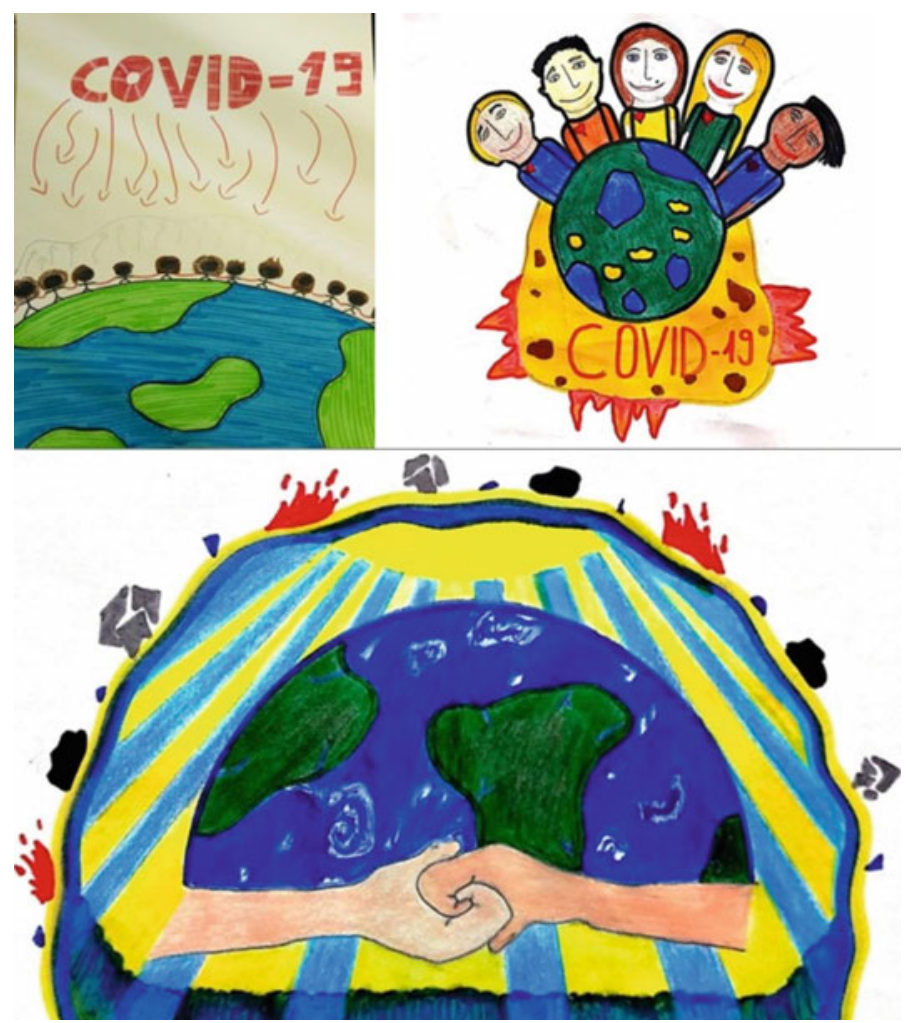

Fig. 8.3 Three drawings by Lithuanian students of the oldest age group depicting the need to stand united, globally, to fight the pandemic. The lefthand corner is titled "All together," the one below "Importance of unity experiencing COVID-19," and the righthand corner "The good work of everybody can improve the bad situation"

during the lockdown (Reuters Staff 2020). Children's COVID-19 lockdown drawings exhibited by The Hindu (2020) again show that children all over the world depict similar themes of the pandemic. Homes, virus visualizations, health campaigns, and the globe are all featured in these reports on COVID-19 drawings. The drawings in our data set differ from the images gathered by these news outlets, because they were made 
for the CLLP. The pictures produced by the students in our study were framed by the themes and pedagogical aims and theme of our project.

\section{CONCLUSIONS: EXCEPTIONS, Peculiarities, ANd Missing Ideas}

As dialogic engagement with cultural difference (including different views on a subject) is central to our idea of cultural literacy learning, it is worth noting that the conformist approach which dominated most of the artifacts in our data makes it impossible to imagine dialogue on the subject. A great deal of the artifacts relating to COVID-19, especially the ones referencing the rules or guidelines, reflect compliance and the internalization of existing health instructions. Many of the artifacts in our data set hence merely recycle the existing coronavirus imagery. This may be because the images were produced as school work. School work naturally reflects the objectives of the given task and the educational aims of the teacher, and, in this case, the project researchers who designed the tasks. This educational frame might also explain why the explicit references to tolerance and empathy often seem so mechanical.

One notable exception to the lack of dialogue could be the Portuguese artifacts, all drawn by students in the oldest age group. Unlike the Lithuanian or Cypriot students, the Portuguese ones were able to choose between two tasks: Either photograph graffiti in their hometown (as proposed in DIALLS lesson 11) or make a face mask with a statement of their own. As Portugal was in lockdown when they did this lesson, all the students produced masks (either pictures of masks or actual masks) which they decorated and combined with statements such as "invisible $\neq$ nonexistent" or "graffiti art $\neq$ vandalism." The "does not equal" rhetoric invites disagreement and discussion-it implies views that actually equate invisibility with nonexistence and graffiti art with vandalism. Invisibility probably points to the invisibility of the virus, but could also be interpreted as invisibility of women in many contexts, as the person wearing the mask in this image is apparently a girl (Fig. 8.4).

These Portuguese students allude to cultural difference on the level of differing opinions or points of view. Some of their artifacts use powerful symbolism by depicting birds in the sky and chains. While the birds can be read as expressions of freedom (longed for in lockdown), the chains can be interpreted in different ways. One possible interpretation is the feeling of being "chained up" indoors caused by the lockdown. When the chain 


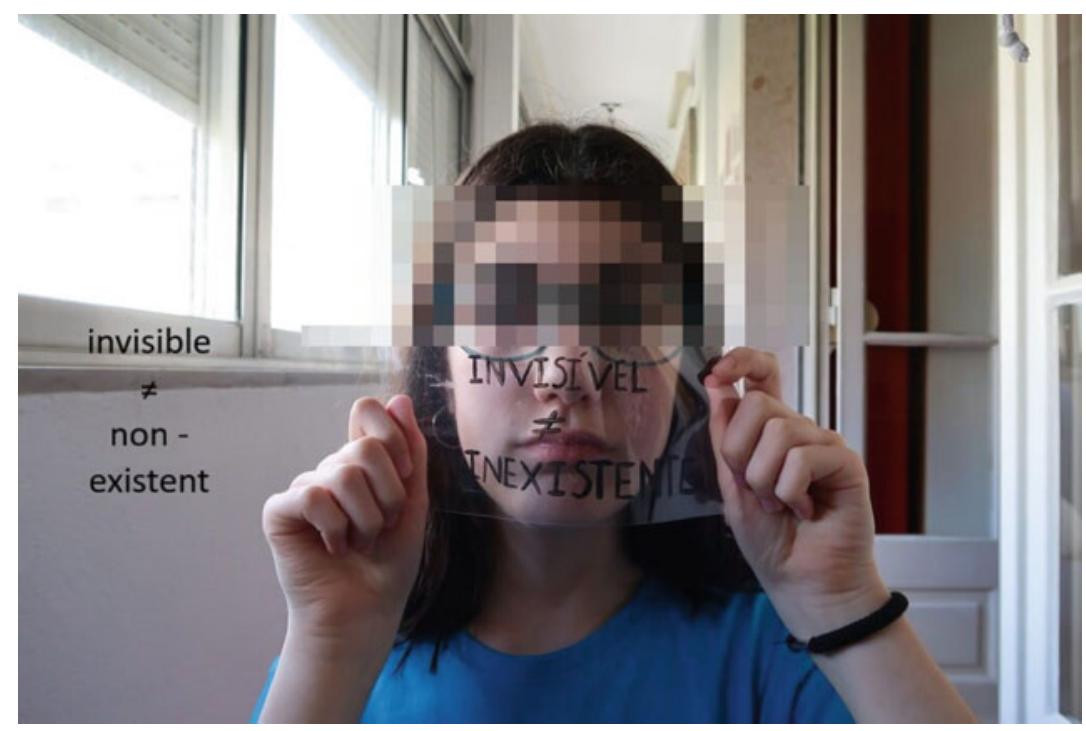

Fig. 8.4 A photograph of a mask with the text invisible $\neq$ nonexistent made by a Portuguese student of the oldest age group

is depicted as breaking, this could depict the need to break the chain of infection. In the lessons on home (see Chapter 7) images of locks and chains signified safety, which is one more possible interpretation, but less likely to be what these students aspired to communicate.

Since these artifacts have no captions, we do not have any additional information on the thoughts of the students who made them. Yet, they refer to the global impact of the pandemic. One mask is decorated with an image of the globe and an equally large virus that looms behind it. Another one features a face painting that follows the round shape, blue and green colors of the globe and features the text "save me."

One of the most striking artifacts is a mask with an image of a uterus. The uterus seems to raise two hands that show the viewer the middle finger-an obscene gesture that represents defiance. This obviously strays quite far from the typical COVID-19 imagery, but links to the abortion debate. In this sense, the mask represents compliance with government rules to overcome the COVID-19 pandemic, yet expresses a clear protest toward other contemporary phenomena. Abortion is a 
hot topic in Portugal and, sometime after these masks were made, there were solidarity protests in Lisbon against the Polish abortion law (Torrisi 2020). Therefore, the mask could be interpreted as an expression of solidarity and empathy with women striving to rule over their own bodies.

In raising questions and making strong, possibly controversial claims, these artifacts could represent a desire to engage in dialogue. Yet it is sometimes hard to determine who they engage with or where this dialogue might lead. For our project, we defined empathy, tolerance, and inclusion as understanding, openness, and including differing views or cultural otherness. Can we detect instances of (differing) viewpoints or cultural otherness within the images or captions? The artifacts within the COVID-19 data set do not contain straightforward references to cultural otherness, but they do express actions to include elderly people on an ideal level at a time when they are very much excluded and isolated from society.

This COVID-19 data set reflects both the official, educational discourses that guided coronavirus imagery in the media and some exceptionally confrontational works that seem to tap into less-discussed issues. Since many of the artifacts include only short titles with no deeper textual elaborations, we are left wondering how these works reflect the themes of empathy, tolerance, and inclusion. As is clear from the analysis above, some of the images can be interpreted in multiple ways, while the claims of others remain somewhat vague.

\section{REFERENCES}

Academy of Finland. 2020. "Call for Applications: Special Funding for Research on COVID-19 Epidemic and the Mitigation of Its Effects." Call opened on April 7, 2020 and closed on April 28, 2020. https://www.aka.fi/en/fun ding/apply-for-funding/apply-now2/call-for-applications-special-funding-forresearch-on-covid-19-epidemic-and-the-mitigation-of-its-effects/.

AFP and N. Lacsina. 2020. "COVID-19: Children's Drawings from Lockdown Show the World What They Miss Most: Regardless of Where They Are, the Themes Are Often the Same." Gulf News, April 23, 2020. https://gulfnews.com/photos/news/covid-19-childrens-drawingsfrom-lockdown-show-the-world-what-they-miss-most-1.1587647481037.

Callard, A. 2020. "What Do the Humanities Do in a Crisis?" The New Yorker, April 11, 2020. https://www.newyorker.com/culture/annals-of-inq uiry/what-do-the-humanities-do-in-a-crisis. 
Kale, S. 2020. "How Coronavirus Helped TikTok Find Its Voice." The Guardian, April 26, 2020. https://www.theguardian.com/technology/ 2020/apr/26/how-coronavirus-helped-tiktok-find-its-voice.

Kovalčic, J., and M. Ryynänen. 2020. "Gazing at the Invisible: How can Aesthetic Theory Help Make Sense of the State of Emergency Initiated by COVID-19?" Popular Inquiry: The Journal of Kitsch, Camp and Mass Culture 2: 2-5. https://staticl.squarespace.com/static/58763ec0c534a5e 7e2b65fe2/t/5e8f04afc2a92a40be994la9/1586431152882/Popular+inq uiry_Vol7_2020_3_JOZEF\%26MAX.pdf.

Landdeck, K. S. 2020. "Why We Should All Be Keeping Coronavirus Journals." Time, April 24, 2020. https://time.com/5824341/wwii-diaries-cor onavirus/.

Marschall, A. 2020. "As Museums Get on TikTok, the Uffizi Is an Unlikely Class Clown." The New York Times, June 24, 2020. https://www.nytimes. com/2020/06/24/arts/design/uffizi-museums-tiktok.html?searchResultPos ition $=63$.

McCarthy, E. and R. O'Rawe. 2020. "Coronavirus: How Artists in the SpanishSpeaking World Turn to Religious Imagery to Help Cope in a Crisis." The Conversation, June 22, 2020. https://theconversation.com/coronavirushow-artists-in-the-spanish-speaking-world-turn-to-religious-imagery-to-helpcope-in-a-crisis-139143.

McKay, C., and T. L. DeCicco. 2020. "Pandemic Dreaming: The Effect of COVID-19 in Dream Imagery, Pilot Study." American Psychological Association 30 (3): 222-234.

Paulino, M., R. Brites, L. Alho, M. R. Simões, and C. F. Silva. 2021. "COVID19 in Portugal: Exploring the Immediate Psychological Impact on the General Population.” Psychology, Health \& Medicine 26 (1): 44-55. https://doi.org/ $10.1080 / 13548506.2020 .1808236$ ? scroll=top\&needAccess=true.

Popescu, A. 2020. "How Will We Remember the Pandemic? Museums Are Already Deciding." The New York Times, May 25, 2020. https://www.nyt imes.com/2020/05/25/arts/design/museums-covid-19-collecting.html?act ion $=$ click \& module $=$ Top $\% 20$ Stories\&pgtype $=$ Homepage .

Reuters Staff. 2020. "Children's Drawings from Lockdown Show the World What They Miss Most." Reuters, April 23, 2020. https://www.reuters.com/ article/us-health-coronavirus-children-drawing-w-idUSKCN2251R3.

Richards, V. 2020. "These Kids Drawings Of Covid Are Genuously Hilarious." The Huffington Post, November 28, 2020. https://www.huffingtonpost. co.uk/entry/kids-have-been-drawing-what-they-think-coronavirus-lookslike_uk_5fc0ca8ec5b68ca87f835dc5.

Robinson, K. S. 2020. "The Coronavirus Is Rewriting Our Imaginations." The New Yorker, May 1, 2020. https://www.newyorker.com/culture/annals-ofinquiry/the-coronavirus-and-our-future. 
Smith, R. P. 2020. "How Smithsonian Curators Are Rising to the Challenge of Covid-19." Smithsonian Magazine, April 15, 2020. https://www.smithsoni anmag.com/smithsonian-institution/how-smithsonian-curators-are-rising-cha llenge-covid-19-180974638/.

Staffordshire University. 2020. "What Can Children's Drawing Tell Us about the Impact of Coronavirus?" Staffordshire University, July 13, 2020. https:// www.staffs.ac.uk/news/2020/07/what-can-childrens-drawing-tell-us-aboutthe-impact-of-coronavirus.

Stylianou, N., and G. Samouti. 2020. "Mental Health Disorders During the COVID-19 Outbreak in Cyprus." Journal of Medicine and Life 13 (3): 300305. https://www.ncbi.nlm.nih.gov/pmc/articles/PMC7550154/.

Taylor, T. 2020. "Kids' Coronavirus Art Reveals How They're Processing the COVID-19 Pandemic." ABC Health and Wellbeing, May 1, 2020. https:// www.abc.net.au/news/health/2020-05-02/kids-art-coronavirus-processingtrauma/12194004.

The New York Times. 2020. "What Are Your Kids Drawing?" August 24, 2020. https://www.nytimes.com/2020/08/24/education/kids-corona virus-drawings.html.

The Hindu. 2020. "Drawings from India in the Times of COVID-19 Lockdown." April 18, 2020. https://www.thehindu.com/children/drawingsfrom-india-in-the-times-of-covid-19-lockdown/article31377328.ece

Torrisi, C. 2020. "From Chicago to Kiev, Women Send Solidarity to Poland after Abortion Ban." Open Democracy Net, November 5, 2020. https://www.opendemocracy.net/en/5050/chicago-kiev-womensend-solidarity-poland-after-abortion-ban/.

UNICEF. 2020a. "Drawings from Children in the Time of the Coronavirus." https://www.unicef.org/romania/stories/drawings-children-timecoronavirus.

UNICEF. 2020b. Facebook post, August 22, 2020. https://www.facebook. $\mathrm{com} /$ unicef/posts/covid-19-through-childrens-drawingsthese-children-inbangladesh-are-using-art-to/10158630198399002/.

University of Amsterdam. 2020. "Research into 'Corona Humour'." Faculty of Social and Behavioural Sciences. https://www.uva.nl/en/shared-content/ faculteiten/en/faculteit-der-maatschappij-en-gedragswetenschappen/news/ 2020/04/corona-humour.

Valko, A. 2020. "Coronavirus: Decoding the Spiky Fuzz-Ball." Lab Report, Michigan Medicine, University of Michigan, July 24, 2020, https://labblog. uofmhealth.org/lab-report/coronavirus-decoding-spiky-fuzz-ball.

Vilnius University Psychotraumatology Center. 2020. "Psichologų patarimai, kaip pagerinti psichologinę savijautą pandemijos metu." https://www.fsf.vu. lt/naujienos/fakulteto-ivykiai/3965-psichologu-patarimai-kaip-pagerinti-psi chologine-savijauta. 
Wilson, N., and T. Frey. 2020. "COVID-19: 'Visualizing the Impact of an Invisible Threat'." McKinsey \& Company, July 2, 2020. https://www.mck insey.com/featured-insights/coronavirus-leading-through-the-crisis/covid19-visualizing-the-impact-of-an-invisible-threat.

Open Access This chapter is licensed under the terms of the Creative Commons Attribution 4.0 International License (http://creativecommons.org/licenses/ by $/ 4.0 /)$, which permits use, sharing, adaptation, distribution and reproduction in any medium or format, as long as you give appropriate credit to the original author(s) and the source, provide a link to the Creative Commons license and indicate if changes were made.

The images or other third party material in this chapter are included in the chapter's Creative Commons license, unless indicated otherwise in a credit line to the material. If material is not included in the chapter's Creative Commons license and your intended use is not permitted by statutory regulation or exceeds the permitted use, you will need to obtain permission directly from the copyright holder.

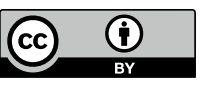

